\title{
Use of the Angularis Oris Axial Pattern Buccal Flap for the Correction of Facial Defects in Six Dogs
}

\author{
Marla Tereza Frasson', Flavio Augusto Vieira Freitag' ${ }^{2}$, Rafael Ricardo Huppes ${ }^{3}$, Josiane Morais Pazzini', \\ Andrigo Barboza de Nardi ${ }^{1}$, Jorge Luiz Costa Castro ${ }^{4}$, Carolina Quarterone ${ }^{3}$ \& Livia Dreer ${ }^{5}$
}

\begin{abstract}
Background: Reconstructive surgery is an important area of veterinary surgery because it allows the reconstruction of large cutaneous defects in areas where a primary approach is not possible. Axial patterns flaps are composed by one direct cutaneous artery and vein, leading to a better blood supply with a good survival outcome. The angularis oris axial pattern buccal flap was introduced for correction of facial defects, but its versatility is not really explored in the existing literature. This article reports the use and complications of the angularis oris axial pattern buccal flap in six dogs, to treat defects in mandibular, temporal or labial regions.

Cases: Five mixed breed dogs and one Labrador, with age between 4 and 9-year-old were submitted for surgery and the angularis oris axial pattern buccal flap was used to close the different defects. Causes of defect included a lesion caused by myiasis in three of the dogs, and tumoral removal in the other three, where two were mast cell tumors and one a keratinizing basal cell carcinoma. The regions affected included rostral mandible with oral mucosa, intermandibular region, temporal region and upper lip. Before flap confection the tissue was cleaned, resected and prepared properly, according to each cause of lesion. The flap was made with two parallel incisions, which center was usually the labial commissure, with the dorsal limits at the ventral aspect of the zygomatic arch, and the ventral incision on the ventral aspect of the mandibular ramus. Caudal extension was based on the length needed for surgical closure, but stained between the vertical auditory canal or up to atlas wing. Suture size and pattern depend the region and patient size. Patients were observed closely for any complication in the surgical site. From the six dogs presented here, five got some complications in the surgical site, including: lymphedema (2), suture dehiscence (4) and hematoma (1); however, regardless the complication, all patients had successful wound healing in 15 to 21 days after surgery. Also, in two of the four suture dehiscence episodes, the cause of dehiscence was secondary to trauma and not the surgery.

Discussion: The reconstruction of facial defects is noteworthy due the limited availability of flaps that can reach the region without excessive tension or healing complications. The angularis oris axial buccal flap pattern is the nearest flap to close defect in the intermandibular, temporal or labial regions. In the cases reported, it is possible to observe that the most frequent complication was suture dehiscence, but it occurred mostly in a small proportion of the flap, allowing healing in the expected time. The surgical planning is an important factor for reconstructive surgeries, so that there is enough tissue for the closure of the recipient and donor site, without tension over the flap or interference with tissue function and aesthetics. Despite the suture dehiscence in some of the cases, all patients showed adequate final recovery, since they returned to normal function with satisfactory cosmetic appearance. The angularis oris axial pattern buccal flap was applied in the correction of defects easily and all patients returned to normal function with satisfactory cosmetic appearance.
\end{abstract}

Keywords: reconstructive surgery, facial reconstruction, cancer, wound, canine. 


\section{INTRODUCTION}

Reconstructive surgery is an important area of veterinary surgery, that allows the reconstruction after traumatic wounds, tumor resection [3], mandibular fractures [12] or even infection and chronic inflammation [9]. The axial pattern flap is composed by one direct cutaneous artery and vein in its extension, leading to a better blood supply, and a more extensive flap with a good survival rate $[9,10]$.

Initially, the angularis oris axial pattern flap was described as a transpositional flap, later it was used as a flap to correct and cover palatal defects, and finally in 2007, reported as an axial pattern flap to close facial skin defects in small animals [13].

The angularis oris axial pattern flap has been described for the correction of big facial defects, such as labial, nasal [10], orbital, intermandibular [9] and palatine [5]. The near location of the angularis oris artery to the defect, favors the usage of this flap, because it is easy to perform and also reduces the surgical time, which is beneficial for the patient $[9,10]$.

According to Losinski et al. [9], there is a limited number of reports describing the versatility and limitations of this flap. Therefore, the objective of this study is to report 6 cases, in which the angularis oris axial pattern flap allowed the healing of wounds in the intermandibular, temporal and labial region in dogs.

\section{CASES}

Six dogs referred for the surgery service, underwent reconstructive surgery to synthesize facial defects caused by either myiasis or tumor resection. Defect locations varied between the rostral jaw, intermandibular, temporal and labial regions. Patient data is summarized at Table 1.

Physical, and laboratory examination, including blood count, renal (urea and creatinine) and hepatic (alamine aminotransferase and albumin) function tests was performed on all patients. The patients with neoplasm (cases number 2, 3 and 4), also underwent chest radiographs and abdominal ultrasound evaluation for metastasis search. None of the patients presented changes in laboratorial or radiographic exams at the time of the surgery.

Case 1. The wound was secondary to the myiasis, caused by the parasite Cochliomyia hominivorax, $24 \mathrm{~h}$ previously to the reconstruction, the patient was submitted to parasite removal and cleaning, using $0.9 \% \mathrm{NaCl}$ solution (Fisiológico $0.9 \%{ }^{1}$ ) and $0.12 \%$ chlorhexidine gluconate-based (Periovet ${ }^{\circledR 2}$ ) buccal solutions in the oral mucosa.

Initially a rostral mandibulectomy was performed, between the first and second premolars with a subsequent surgical debridement and removal of contaminated skin, followed by cleaning with $0.9 \%$ $\mathrm{NaCl}$ solution. To make the flap, two parallel incisions were created, in which the center was located in the

Table 1. Information about six dogs submitted to the angularis oris axial buccal pattern flap.

\begin{tabular}{|c|c|c|c|c|c|c|}
\hline Parameter & 1 & 2 & 3 & 4 & 5 & 6 \\
\hline Sex & Male & Male & Male & Male & Female & Male \\
\hline Breed & MBD & Labrador & MBD & MBD & MBD & MBD \\
\hline Age (years) & 4 & 9 & 6 & 9 & 9 & 7 \\
\hline $\begin{array}{c}\text { Cause of the } \\
\text { lesion }\end{array}$ & Myiasis & $\begin{array}{c}\text { Keratinizing } \\
\text { basal cell } \\
\text { carcinoma }\end{array}$ & $\begin{array}{l}\text { Mast cell } \\
\text { tumor* }\end{array}$ & $\begin{array}{l}\text { Mast cell } \\
\text { tumor } * *\end{array}$ & Myiasis & Myiasis \\
\hline $\begin{array}{l}\text { Localization } \\
\text { of the lesion }\end{array}$ & $\begin{array}{c}\text { Rostral } \\
\text { mandible and } \\
\text { oral mucosa }\end{array}$ & $\begin{array}{l}\text { Intermand- } \\
\text { ibular region }\end{array}$ & $\begin{array}{l}\text { Temporal } \\
\text { region }\end{array}$ & $\begin{array}{l}\text { Temporal } \\
\text { region }\end{array}$ & $\begin{array}{l}\text { Temporal } \\
\text { region }\end{array}$ & Upper lip \\
\hline Complications & None & $\begin{array}{l}\text { Lymphedema } \\
\text { and suture } \\
\text { dehiscence }\end{array}$ & $\begin{array}{l}\text { Suture dehis- } \\
\text { cence }\end{array}$ & $\begin{array}{c}\text { Hema- } \\
\text { toma and } \\
\text { lymphedema }\end{array}$ & $\begin{array}{l}\text { Suture dehis- } \\
\text { cence }\end{array}$ & $\begin{array}{l}\text { Suture dehis- } \\
\text { cence }\end{array}$ \\
\hline
\end{tabular}

MBD: Mixed breed dog; *Grade II mast cell tumor in the Patnaik classification [11], high grade in the Kiupel classification [8]. ** Grade III mast cell tumor in the Patnaik classification [11], high grade in the Kiupel classification [8]. 
labial commissure, with the dorsal incision limited by the ventral aspect of the zygomatic arch, and the ventral incision, the ventral aspect of the mandibular ramus (Figure 1-A). The flap was extended caudally to the vertical auditory canal, and carefully raised to avoid injuries at the angularis oris artery. Afterwards, the flap was positioned over the receptor site, the rostral aspect of the mandible.

Skin sutures for the donor site and the flap was sutured at the oral mucosa, with a simple interrupted suture pattern using 2-0 nylon thread (Figure 1-B). Immediately after the procedure, a pharyngostomy was performed for further feed. The patient was kept at the veterinary hospital for 7 days with water intake and liquid feeding only through the esophageal tube. On the $13^{\text {th }}$ day, complete wound healing was noted, and the stiches were removed, allowing the removal of the esophageal tube on the $15^{\text {th }}$ day, after patient was adapted to oral feeding (Figure 1-C).

Case 2. A keratinizing basal cell carcinoma was excised in the intermandibular region, with subsequent flap confection, using as landmarks the same limits of the previous case (Figure 2-A). The submandibular lymph node excision was performed using the same

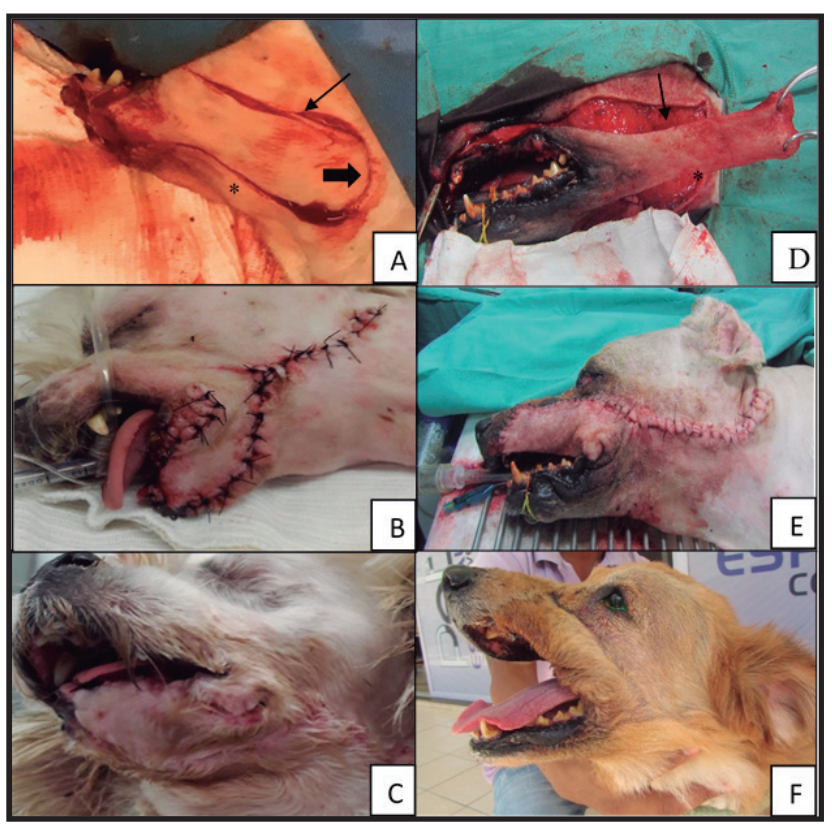

Figure 1. Photographic images of the cases 1 (A to C) and 6 (D to F). A- Confection of the flap using the ventral aspect of the zygomatic arch (arrow), as the limit for the dorsal incision, and the ventral aspect of the mandibular ramus $(*)$ as the limit of the ventral incision. The flap was extended caudally to the vertical ear canal (filled arrow). B- Immediate postoperative picture. C- Total healing on the 15 th postoperative day. DThe flap was made using the ventral aspect of the zygomatic arch (arrow), the ventral aspect of the mandibular ramus $(*)$ and the atlas wing, as its limits for the incision. E- Immediate postoperative picture. F- Donor site and flap healed on the 45th postoperative day.

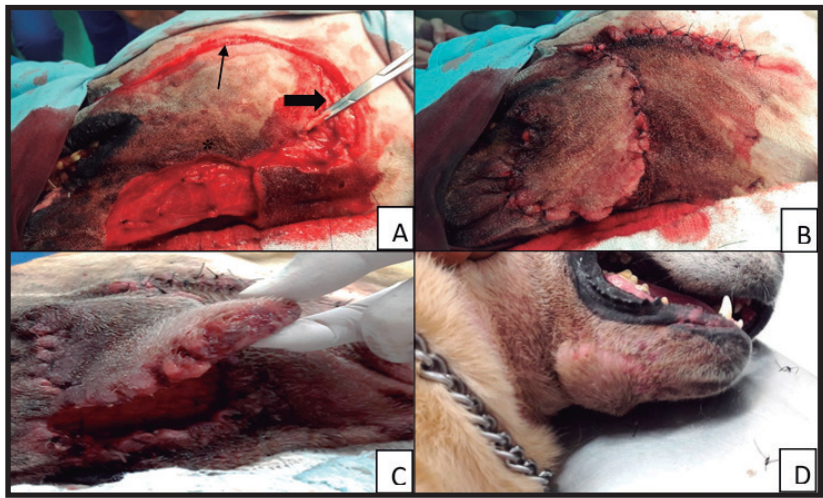

Figure 2. Photographic image of the case 2. A- Confection of the flap using the ventral aspect of the zygomatic arch (arrow), as the limit for the dorsal incision, and, for the ventral incision, the ventral aspect of the mandibular ramus (*). The flap was extended caudally to the vertical ear canal (filled arrow). B- Immediate postoperative picture. C- Suture dehiscence on the 7 th day after surgery. D- Total healing on the 21 st day after the first surgery (Figure 2. A).

incision made to create the flap. Subsequently, the flap was positioned over the recipient site, and simple interrupted suture pattern with 2-0 nylon. The edges of the donor site were approximated using walking suture pattern with 25 2-0 polyglecaprone thread and the skin suture of the flap and the donor site were performed with simple interrupted suture pattern with sultan stiches using 2-0 nylon thread (Figure 2-B).

Four days after surgery, the patient had sings of lymphedema on the face and flap and was treated with oxerutin [Venoruton ${ }^{\circledR 3}, 500 \mathrm{mg} / \mathrm{BID} /$ P.O./ 5 days] and ice pack [20 min / TID/ 3 days]. Although the edema was resolved after therapy, suture dehiscence throughout the flap was noticed, without necrosis (Figure 2-C). On the 7th postoperative day, surgical debridement and new wound synthesis were performed, enabling proper healing and removal of the stitches 21 days after the first surgery (Figure 2-D). Even without margin evaluation, the patient was followed for 425 days without recurrence (Figure 2).

Case 3. A mastocytoma excision at the temporal region was performed (Figure 3-A) with a subsequent angularis oris axial pattern flap confection, using the previously described dorsal and ventral limits, but now extending caudally up to the atlas wing. The dead space of the donor site was reduced by using a simple continuous zigzag pattern with 2-0 25 polyglecaprone thread, and subsequently the cutaneous synthesis in a simple interrupted suture pattern with 2-0 nylon. In the receptor site, only 2-0 nylon sultan pattern suture was performed, without reduction of the dead space (Figure 3-B). 


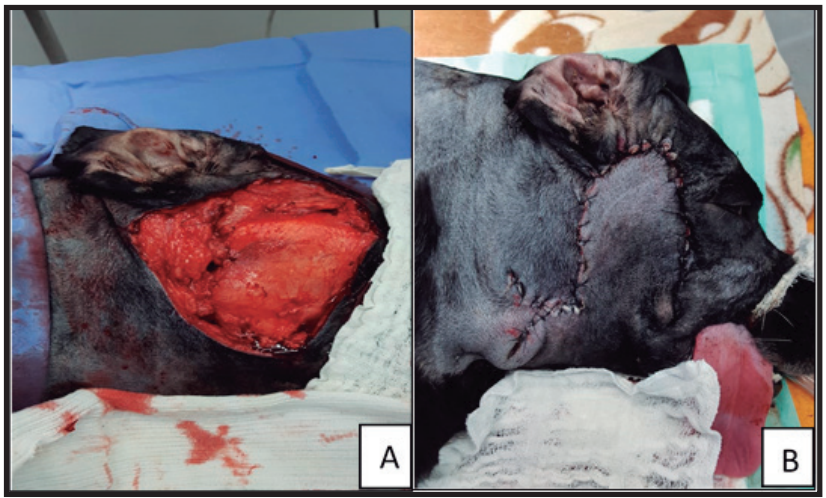

Figure 3. Photographic images of case 3. A- Defect created after mast cell tumor excision. B- Immediate postoperative picture.

Twenty-four h after surgery, the flap showed hematoma, which was controlled with topic applications of diethylammonium salicylate $\left[\right.$ Reparil $^{\circledR} \mathrm{Gel}^{4}$, TID/ 5 days]. On the 12th postoperative day, there was dehiscence of 2 stiches, which was clinically treated using $1 \%$ silver sulfadiazine-based ointment, allowing complete healing in 21 days.

Case 4. The $1 \%$ methylene blue technique was used for mandibular, parotid and retropharyngeal lymph nodes removal. Subsequently, the resection o the mast cell in the temporal region was performed with subsequent angularis oris axial pattern flap, as described in case number 3 (Figure 4-A). A hematoma was observed in the flap, $24 \mathrm{~h}$ after the surgery, and therapy with local application of diethyl ammonium salicylate [Reparil ${ }^{\circledR}$ Gel, TID/ 5 days] was instituted. This patient also had lymphedema for $72 \mathrm{~h}$, which was controlled using ice pack [20 min / TID/ 3 days]; however, there was no suture dehiscence and the patient had complete healing in 15 days after surgery (Figure 4-B). Tumor margins evaluation was nor performed in cases 3 and 4.

Case 5. After surgical debridement of the lesion caused by myiasis by the parasite Cochliomyia hominivorax in the temporal region, the defect was measured with the flap being made subsequently. For the synthesis of the donor site, simple continuous in zigzag with 3-0 gluconate thread was used to approximate the tissue, for the donor and receptor site, the skin was closed with a simple interrupted pattern with 3-0 nylon thread or 3-0 polydioxanone in the gingival mucosa region. Suture dehiscence was observed on the $4^{\text {th }}$ postoperative day, secondary to trauma, which was resolved with surgical debridement and subsequent

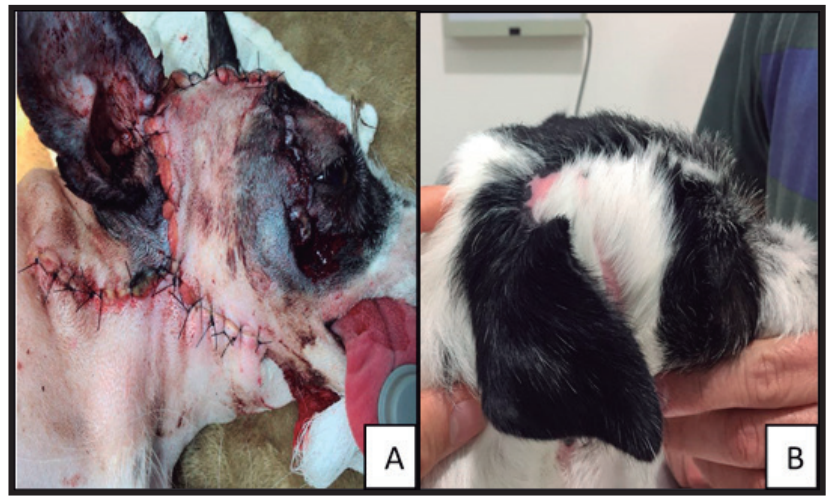

Figure 4. Photographic image of case 4. A- Immediate postoperative of the flap, which used the ventral aspect of the zygomatic arch, the ventral aspect of the mandibular ramus and the wing of the atlas, as its limits for the incision. B- Healing process completed.

synthesis and compressive bandage. The stitches were removed 15 days after the first surgery.

Case 6. Dog had an injury secondary to myiasis, by the same parasite as case number 5 , on the upper lip with loss of the entire buccal and gingival mucosa between the canine and first upper molar tooth, leaving the oral cavity exposed. For the repair of the lesion, it was opted for the angularis oris axial pattern flap, which was made with the atlas wing as the caudal limit (Figure 1-D). The flap was rotated over the defect in the upper lip and the synthesis of the inner face of the flap to the gingiva was made in a simple interrupted pattern with 4-0 25 polyglecaprone. The cutaneous edge was approximated using an interrupted intradermal pattern with 4-0 25 polyglecaprone and the dermorrhaphy in a simple interrupted pattern using 3-0 nylon thread (Figure 1-E). On the 15 th postoperative day there was complete healing and the stitches were removed; however, after 16 days of stiches removal, the patient returned with a small area of suture dehiscence, probably caused by trauma. A next skin synthesis was performed in a simple interrupted pattern using 3-0 nylon thread, whose stiches were removed 15 days after, when complete healing was noted (Figure 1-F).

All patients were kept with an Elizabethan collar until complete healing of the surgery incision. The surgical wound was cleaned daily with $0.9 \%$ sodium chloride solution. Patients received antibiotics, analgesics and non-steroidal anti-inflammatory drugs after surgery.

\section{DISCUSSION}

The reconstruction of facial defects is noteworthy due the limited availability of flaps that reach the 
region without excessive tension or healing complications. The angularis oris axial buccal flap pattern is the nearest flap to close defect in the intermandibular, temporal or labial regions, minimizing the flap size and consequently it complications.

According to Losinski et al. [9], subdermal flaps of transposition have a greater chance of necrosis when compared to axial pattern flaps due to the absence of a direct artery and vein at the base of the flap, therefor, axial pattern flaps should be prioritized to correct large defects in the face. In the cases reported, it is possible to observe that the most frequent complication was suture dehiscence, but it occurred mostly in a small proportion of the flap, allowing healing in the expected time. In addition, even in case two, in which there was a total flap dehiscence, no necrosis was observed.

In the literature, there are other options for flaps with an axial pattern to correct facial defects, with different limitations, such as the superficial temporalis, which has a small caliber and small angiosome extension [6] and the caudal auricular [12], which is more distant and therefore has a greater chance of necrosis at its extremity.

Among the subdermal pattern flaps that can be used in the face, the advancement flap, despite its easy use, has limited length and width. Tubular flaps, require 14 to 21 days after the tube was made to be relocated over the lesion [4] and, therefore, is not always viable for the patient. Rotation flaps, even not being described in the literature for correcting facial defects, should be explored as an option for the synthesis of defects in the intermandibular region, since the cervical region is rich in skin and there would be no tension in the suture, even with the movement.

Although the vascularization of the angularis oris axial buccal pattern flap allows the length to be extended to the wing of the atlas, Yates et al. [13] reported a case in which the flap was performed up to this limit and presented suture dehiscence on it the distal portion. In cases number 4,5 and 6 , the caudal limits of the flap were the wing of the atlas, and there was complete healing in the expected time, but with dehiscence in cases 5 and 6 , associated with trauma.

In case 1 , the wound caused by myiasis was contaminated and, therefore, was carefully debrided and cleaned before surgical reconstruction. Due to the need to suture the oral mucosa in the skin, it was opted for tube feeding, since oral feeding could mechanically damage the region, leading to suture dehiscence. Anyway, the healing occurred without complications in this patient.

Mast cell tumors are frequently presented in the head region [1], being common the use of flaps in the surgical planning to enable neoplastic removal with free margins. Edema and delayed healing are common complications in mast cell tumor resection due to the release of heparin, histamine and proteases from the mast cell granules [1]. In our study, case three had minimal suture dehiscence, with minimal clinical importance, and case four presented only hematoma and lymphedema, which were resolved with medical treatment without progressing to healing failure. However, surgical margins evaluation was not being carried out, which makes it impossible to conclude whether there is an influence on healing or not.

In cases 2 and 4, patients presented lymphedema, probably secondary to lymphadenectomy. In case 2, severe edema caused suture dehiscence of the entire lap, requiring a second surgical intervention. However, there was no necrosis of any portion of the flap, allowing the wound to be debrided and sutured again, followed by proper healing. In case 4 , there was no need for a new intervention, and the complications was resolved with conservative medical treatment, as previously described.

Finally, surgical planning is an important factor so that there is enough tissue for the closure of the recipient and donor site, without tension over the flap or interference with tissue function and aesthetics [12]. Despite the suture dehiscence in some of the cases, all patients showed adequate final recovery, since they returned to normal function with satisfactory cosmetic appearance.

The angularis oris axial buccal pattern flap showed a satisfactory result for the correction of defects from various causes, being able to promote the synthesis of extensive wounds on the face, without tension, and offering a pleasant cosmetic aspect. Therefore, it can be suggested as a good option for patients with facial defects.

\section{MANUFACTURERS}

${ }^{1}$ Equiplex. Aparecida de Goiânia, GO, Brazil.

${ }^{2}$ Vetnil Industria e Comércio de Produtos Veterinários Ltda. Louveira, SP, Brazil.

${ }^{3}$ Novartis Biociências S.A. São Paulo, SP, Brazil.

${ }^{4}$ Takeda Pharma AG. João Aldo Nassif, SP, Brazil. 
Acknowledgments. Faculdade de Ciências Agrárias e Veterinárias FCAV/UNESP - Jaboticabal, Unicesumar, Maringá, e Universidade Pontifícia Católica do Paraná (PUCPR), Curitiba.

Ethical approval. The authors of this article, entitled "Use of the angularis oris axial pattern buccal flap for the correction of facial defects in six cases". Declare, for all purposes, that the project that gave rise to the present report was not submitted to evaluation for the Ethics Committee of the Faculdade de
Ciências Agrárias e Veterinárias (FCAV) from the Universidade Estadual Paulista (UNESP), Jaboticabal, SP. However, we are aware of the content of the Brazilian resolutions of the National Council for the Control of Animal Experimentation (CONCEA).

Declaration of interest. The authors report no conflicts of interest. The authors alone are responsible for the content and writing of this paper.

\section{REFERENCES}

1 Blackwood L., Murphy S., Buracco P., De Fornel-Thibaud P., Hirschberger J., Kessler M., Pastor J., Ponce F., Savary-Bateille K. \& Argyle D.J. 2012. European consensus document on mast cell tumours in dogs and cats. Veterinary and Comparative Oncology. 10(3): 1-29.

2 Bryant K.J., Moore K. \& McAnulty J.F. 2003. Angularis Oris Axial Pattern Buccal Flap for Reconstruction of Recurrent Fistulae of the Palate. Veterinary Surgery. (32): 113-119.

3 Castro J.L.C., Huppes R.R., de Nardi A.B. \& Pazzini J.M. 2015. Introdução à anatomia. In: Princípios e Técnicas de Cirurgias Reconstrutivas da Pele de Cães e Gatos (Atlas Colorido). Curitiba: Medvep, pp.10-16.

4 Degner D.A. 2007. Facial Reconstructive surgery. Clinical Techniques in Small Animal Practice. 22(2): 82-88.

5 Dicks N. \& Boston S. 2010. The use of an angularis oris axial pattern flap in a dog after resection of a multilobular osteochondroma of the hard palate. Canadian Veterinary Journal. (51): 1274-1278.

6 Huppes R.R., Castro J.L.C., de Nardi A.B. \& Pazzini J.M. 2015. Técnicas reconstrutivas em cabeça e pescoço. In Princípios e Técnicas de Cirurgias Reconstrutivas da Pele de Cães e Gatos (Atlas Colorido). Curitiba: Medvep, pp.103-119.

7 Kapusniak V. \& Dzimira S. 2006. Basal cell carcinoma. Medycyna Weterynaryjne. 62(3): 270-273.

8 Kiupel M., Webster J.D., Bailey K.L., Best S., DeLay J., Detrisac C.J., Fitzgerald S.D., Gamble D., Ginn P.E., Goldschmidt M.H., Hendrick M.J., Howerth E.W., Janovitz E.B., Langohr I., Lenz S.D., Lipscomb T.P., Miller M.A., Misdorp W., Moroff S., Mullaney T.P., Neyens I., O’Toole D., Ramos-Vara J., Scase T.J., Schulman F.Y., Sledge D., Smedley R.C., Smith K., W Synyder P., Southorn E., Stedman N.L., Steficek B.A., Stromber P.C., Valli V.E., Weisbrode S.E., Yager J., Heller J. \& Miller R. 2011. Proposal of a 2-Tier Histologic Grading System for Canine Cutaneous Mast Cell Tumors to More Accurately Predict Biological Behavior. Veterinary Pathology. 48(1): $147-155$.

9 Losinski S.L., Stanley B.J., Schallberger S.P., Nelson L.L. \& Towle Millard H.A. 2015. Versatility of the Angularis Oris Axial Pattern Flap for Facial Reconstruction. Veterinary Surgery. (44): 930-938.

10 Milgram J., Weiser M., Kelmer E. \& Benzioni H. 2011. Axial Pattern Flap Based on a Cutaneous Branch of the Facial Artery in Cats. Veterinary Surgery. 40: 347351.

11 Patnaik A.K., Ehler W.J. \& MacEwen E.G. 1984. Canine Cutaneous Mast Cell Tumor: Morphologic Grading and Survival Time in 83 dogs. Veterinary Pathologic. (21): 469-474.

12 Pope E.R. 2006. Head and facial wounds in dogs and cats. Veterinary Clinics of North America Small Animal Practice. (36): 793-817.

13 Yates G., Landon B. \& Edwards G. 2007. Investigation and clinical application of a novel axial pattern flap for nasal and facial reconstruction in the dog. Australian Veterinary Journal. 85(3): 113-118. 